\title{
Non-targeted Metabolomic Profiling of Maize Landraces (Zea mays L.) Combined with Chemometric Tools
}

\author{
Virgílio Gavicho Uarrota ${ }^{1,2^{*}}$, Miguel Rocha $^{3}$ and Marcelo Maraschin ${ }^{2}$ \\ ${ }^{1}$ Agroveterinary Science Center, Department of Agronomy, Postgraduate Program in Plant \\ Production, University of the State of Santa Catarina, Lages, Santa Catarina, Brazil. \\ ${ }^{2}$ Plant Morphogenesis and Biochemistry Laboratory, Federal University of Santa Catarina, 1346, \\ Admar Gonzaga Road, Florianópolis, Santa Catarina State, 88034001, Brazil. \\ ${ }^{3}$ Centre of Biological Engineering, University of Minho, Campus de Gualtar, 4710-057 Braga,
}

Portugal.

\section{Authors' contributions}

This work was carried out in collaboration between all authors. Author VGU designed the study, performed the statistical analysis and wrote the first draft of the manuscript. Authors MR and MM supervised, corrected the draft and contributed in data analysis. All authors read and approved the final manuscript.

Article Information

DOI: $10.9734 / I J B C R R / 2017 / 35832$ Editor(s):

(1) Richard A. Manderville, Professor, Departments of Chemistry and Toxicology University of Guelph, Canada.

Reviewers:

(1) Birsa Mihail Lucian, Alexandru loan Cuza University of lasi, Romania.

(2) Leo Baldenegro, Mexico.

(3) Md. Nazmul Haque, Sher-e-Bangla Agricultural University, Bangladesh. Complete Peer review History: http://www.sciencedomain.org/review-history/21869

Original Research Article

Received $31^{\text {st }}$ July 2017 Accepted $21^{\text {st }}$ August 2017 Published 11 ${ }^{\text {th }}$ November 2017

\section{ABSTRACT}

Grain samples of maize landraces were collected and subjected to Fourier Transform Infrared spectroscopy (FTIR) analysis combined with chemometric tools in other to discriminate them regarding the chemical composition. Principal component analysis (PCA) and hierarchical clustering (HCA) were applied on selected peaks of the spectral data. The most important chemical groups found in all maize landrace samples were monoterpenes, sesquiterpenes, tetraterpenes, aminoacids, polysaccharides, lipids and proteins. Trace signals of secondary metabolites were also found in cultivars according to year of harvest.

*Corresponding author: E-mail: uaceleste@yahoo.com.br; 
Keywords: Chemical composition; FTIR; maize landraces; Non-supervised techniques; $R$ software.

\section{INTRODUCTION}

Commonly referred to as maize or corn, Zea mays ssp. mays is one of the world's most important crop plants, achieving a multibillion dollar annual revenue. In addition to its agronomic importance, maize has been a keystone model organism for basic research for nearly a century [1-2]. According to Dwivedi [1], the current industrial agriculture system may be the single most important threat to maize biodiversity. A serious consequence of biodiversity loss is the displacement of locally adapted maize landraces with adaptation traits to future climates by mono-cropping with genetically uniform hybrids and improved cultivars.

Maize landraces represent heterogeneous, local adaptations of domesticated species, and thereby provide genetic resources that meet current and new challenges for farming in stressful environments. These local ecotypes can show variable phenology and low-to-moderate edible yield, but are often highly nutritious. The main contributions of maize landraces to plant breeding have been traits for more efficient nutrient uptake and utilization, as well as useful genes for adaptation to stressful environments such as water stress, salinity, and high temperatures [1, 3-5].

Systematic maize landraces evaluation may define patterns of diversity, which will facilitate identifying alleles for enhancing yield and abiotic stress adaptation, thus raising the productivity and stability of staple crops in vulnerable environments [1, 3-5]. In other hand, regarding the evaluation tools, metabolomics has recently been claimed as a promising concept and valuable tool in biotechnology, given its extensive range of applications in functional genomics and, more globally, in the characterization of biological systems [6]. Indeed, the possible tasks include studying metabolic systems, measuring biochemical phenotypes, understanding and reconstructing networks and discriminating between samples [6]. In the targeted metabolomics approach, specific metabolites of known identity are profiled; good quantitative precision is typically obtained. On the other hand, untargeted metabolomics aims to simultaneously measure as many metabolites as possible in a biological specimen [7].

Taking into account that maize landraces are currently being replaced by new improved cultivars with a narrow genetic basis in Brazilian agriculture and with a purpose to add value of those important genetic materials, the present study was designed with the main goals of investigating the chemical composition of maize landraces using non-targeted metabolomic approach (Fourier Transformed Infrared Spectroscopy-FTIR) combined with chemometric tools (PCA and HCA)as a rapid diagnostic tool to ascertain changes in chemical composition.

\section{MATERIALS AND METHODS}

\subsection{Maize Landraces}

Maize landraces (Zea mays L.) were kindly provided by small farmers of the Anchieta County (the western part of Santa Catarina state, southern Brazil, $26^{\circ} 31^{\prime} 11^{\prime \prime} \mathrm{S}, 53^{\circ} 20^{\prime} 26^{\prime \prime} \mathrm{W}$ ) and produced under agro-ecological management practices during three different harvests (2007, 2008, 2009) Table 1 presents the details of the cultivars used each year). Maize grains were collected, dried and crushed to obtain fine powder for later analysis by Fourier transform infrared spectroscopy (FT-IR).

\subsection{Flour Sample Preparation}

Maize grains (250g - dry weight) were selected from each maize genotype and ground to pass a $0.5 \mathrm{~mm}$ sieve using a laboratory cyclone mill (MB Braeski C.Q).

\subsection{Fourier Transform Infrared Spectroscopy}

FTIR spectra of maize flours were recorded in a Bruker IFS-55 (Model Opus v. 5.0, Bruker Biospin, Germany) spectrometer with a DTGS detector equipped with a golden gate single reflection diamond attenuated total reflectance (ATR) accessory $\left(45^{\circ}\right.$ incidence-angle). A background spectrum of the clean crystal was acquired and samples $(100 \mathrm{mg})$ were spread and measured directly after pressing them on the crystal. The spectra were recorded at the absorbance mode from 4000 to $500 \mathrm{~cm}^{-1}$ at the resolution of $4 \mathrm{~cm}^{-1}$. Five replicate spectra were collected for each sample. For pre-processing, the spectra were normalized, baseline-corrected in the region of interest by drawing a straight line before resolution enhancement ( $k$ factor of 1.7). The assumed line shape was Lorentzian with a half width of $19 \mathrm{~cm}^{-1}$ [8-11]. 
Table 1. Maize landrace cultivars studied in this research during the three years

\begin{tabular}{lll}
\hline Year & Maize cultivar & Acronym \\
analyzed & used \\
\hline \multirow{4}{*}{2007} & Cultivar7 & CULT7 \\
& Cultivar10 & CULT10 \\
& Cultivar11 & CULT11 \\
& Cultivar12 & CULT12 \\
& Cultivar15 & CULT13 \\
& Cultivar17 & CULT15 \\
Lingua De Papagaio & CULT17 \\
& Mato Grosso-Palha Roxa & LP0 \\
& Movimento De Pequenos & MPA10 \\
& Agricultores & \\
& Palha Roxa & PR0 \\
& Rajado 8 Carreiras & R8C0 \\
& Rajado & RJ0 \\
& Roxo & RX0 \\
& Roxo De Emílio & RXE0 \\
& Lingua De Papagaio & LP1 \\
& Mato Grosso-Palha Roxa & MG1 \\
Movimento De Pequenos & MPA11 \\
& Agricultores & \\
Palha Roxa & PR1 \\
Rajado 8 Carreiras & R8C1 \\
Roxo & RX1 \\
Roxo De Emílio & RXE1 \\
\hline
\end{tabular}

\subsection{Chemometric Analysis}

FT-IR spectra were acquired and subjected to chemometric analysis using the R software [12]. Non-targeted metabolomics was used to find variations in the chemical composition of different cultivars, cultivated under different harvests and environmental conditions. FT-IR spectra were acquired in transmittance mode and then transformed to absorbance mode, as spectra objects in the ChemoSpec package [13] using the equation 1.

$$
[A=-\log 10(T)]
$$

where $A$ is the absorbance and $T$ the transmittance

The spectra object was then converted to a hyperSpec [14] object using the bridging package hyperChemoBridge [15]. Before applying chemometric tools, the spectra were baseline corrected, intensity vector normalized and smoothed for subsequent analysis of PCA and HCA [6] for sample classification according to their biochemical status.

\section{RESULTS AND DISCUSSION}

\subsection{Peak Selection and Multivariate Analysis}

Results of the assignments for the most characteristic FTIR bands found in maize landraces and related chemical group are summarized in Table 2. The most important chemical groups found in all maize landrace samples were monoterpenes, sesquiterpenes, tetraterpenes, aminoacids, polysaccharides, lipids and proteins (Table 2).

The intensity of peaks is also shown in the Fig. 1 (A-C) for maize samples from 2007, 2008 and 2009 respectively. The selected peaks found in Fig. 1 were subjected for further multivariate analysis aiming to find similarities or differences between maize samples.

Principal component analysis of the 2007 maize landraces shown in the Fig. 2A. Differences between cultivars were observed. Cultivars (11 and 12$)$ and $(7,17)$ grouped together. The total variance explained by the first 2 PCs was $94.4 \%$, being $80.42 \%$ for PC1 and $13.98 \%$ for PC2. Cultivars 7 and 17 grouped together duo to similarities in amylose, amylopectin and lutein contents. Cultivar 10 grouped alone duo it's content in fatty acids.

PCA of 2008 samples is represented in the Fig. 2B. PC1 explained $43.09 \%$ and PC2 $39.81 \%$, respectively. A good separation was found between PRO, MPA10 and LP0 cultivars. PRO was most correlated to lipids or fatty acids and LPO correlated to amylose, amylopectin, monoterpenes and proteins. PCA on 2009 maize samples is represented in Fig. 2C. PC1 explained $62.64 \%$ and PC2 $(27.31 \%)$ of the total variance. The loading plot indicated that cultivars MG1, LP1, RX1 and RXE1 are similar in chemical composition duo to their values of amylose, amylopectin and fatty acids. Cultivars R8C1 and PR1 showed to be similar duo to their lower levels of proteins and lipids.

When FTIR data of 2007, 2008 and 2009 were subjected to hierarchical clustering (Fig. $3 A-C$ ) aiming to find similarities or differences between samples and look for important wave bands related to sample clustering, an interesting result can be observed and the main bands responsible for sample differences were found. Differences in the 2007 dataset were mainly due 
to the region of carbohydrates $(998,1012$ and 3000). Cultivar 15 grouped alone, and the most similar in chemical composition were cultivars 7 and 17,11 and 12 respectively (Fig. 3A).

For samples of 2008 harvest, the region of proteins, amylose and amylopectin was most important in sample dissimilarity. PRO and
MPA10 were the most dissimilar cultivars (Fig. $3 \mathrm{~B})$. Two visible groups were found; being the first composed by LPO and RXEO and second group by RX0, MG0, RJO and R8C0. For maize landraces of2009 (Fig. 3C), proteins derived the sample clustering. MPA11 and LP1 were the most dissimilar cultivars confirming that observed previously in PCA analysis.
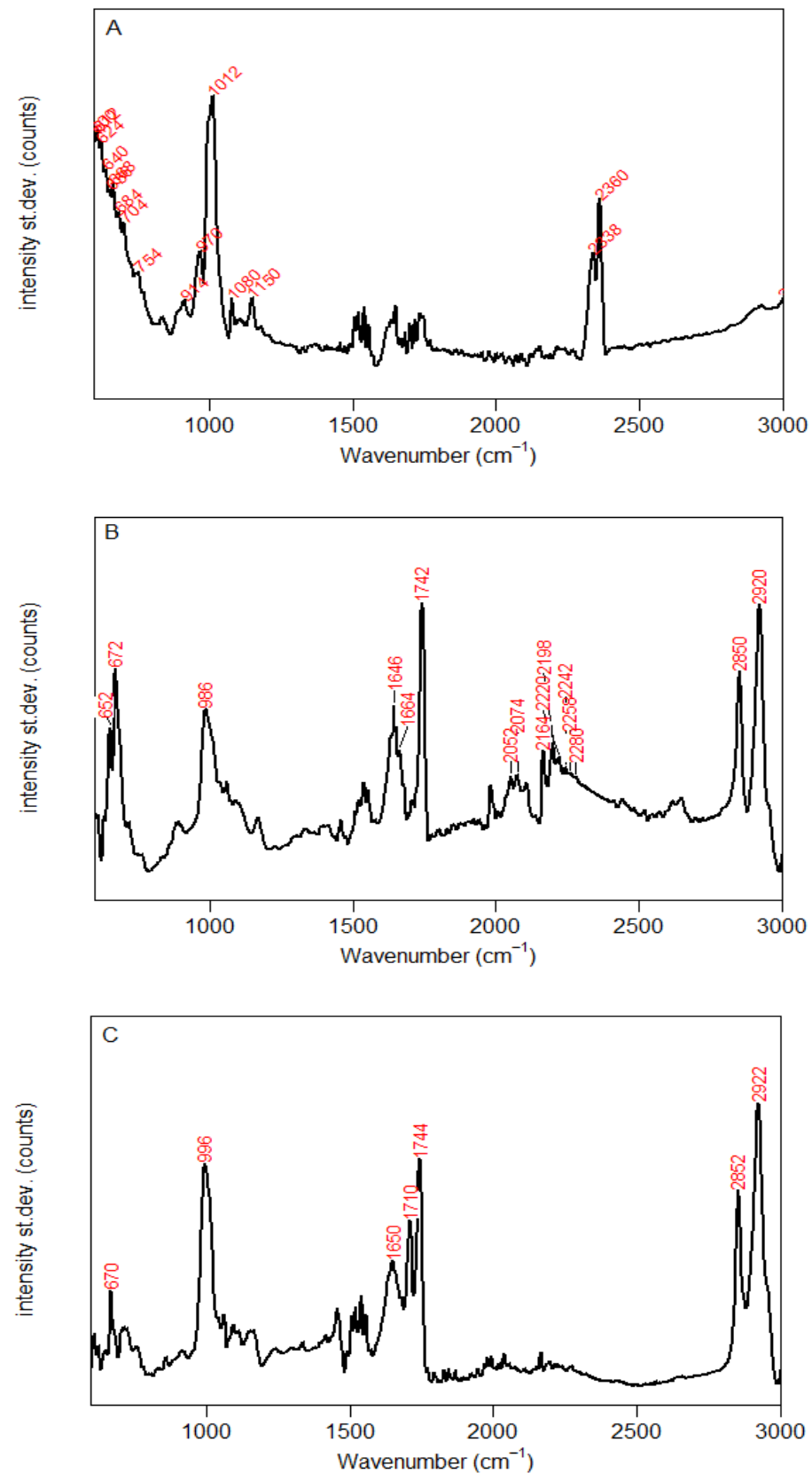

Fig. 1. Main peaks found in FTIR spectra of (A) maize landraces produced in 2007, (B) 2008, (C) maize landraces produced during 2009 harvest, respectively 


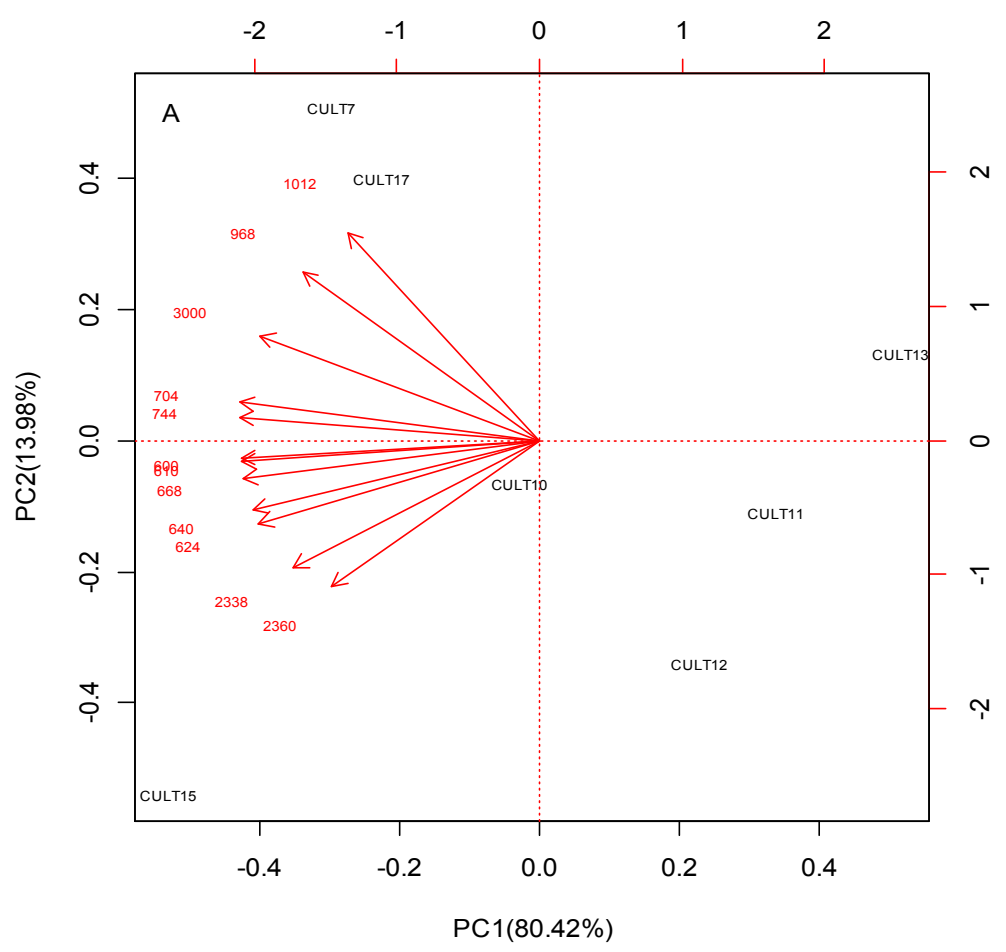

Fig. 2. Score and loading plots of Principal component analysis (PCA) of the whole spectral range $\left(600-3000 \mathrm{~cm}^{-1}\right)$ showing the sample clustering according to their similarities. (A) Maze landraces produced during 2007 year

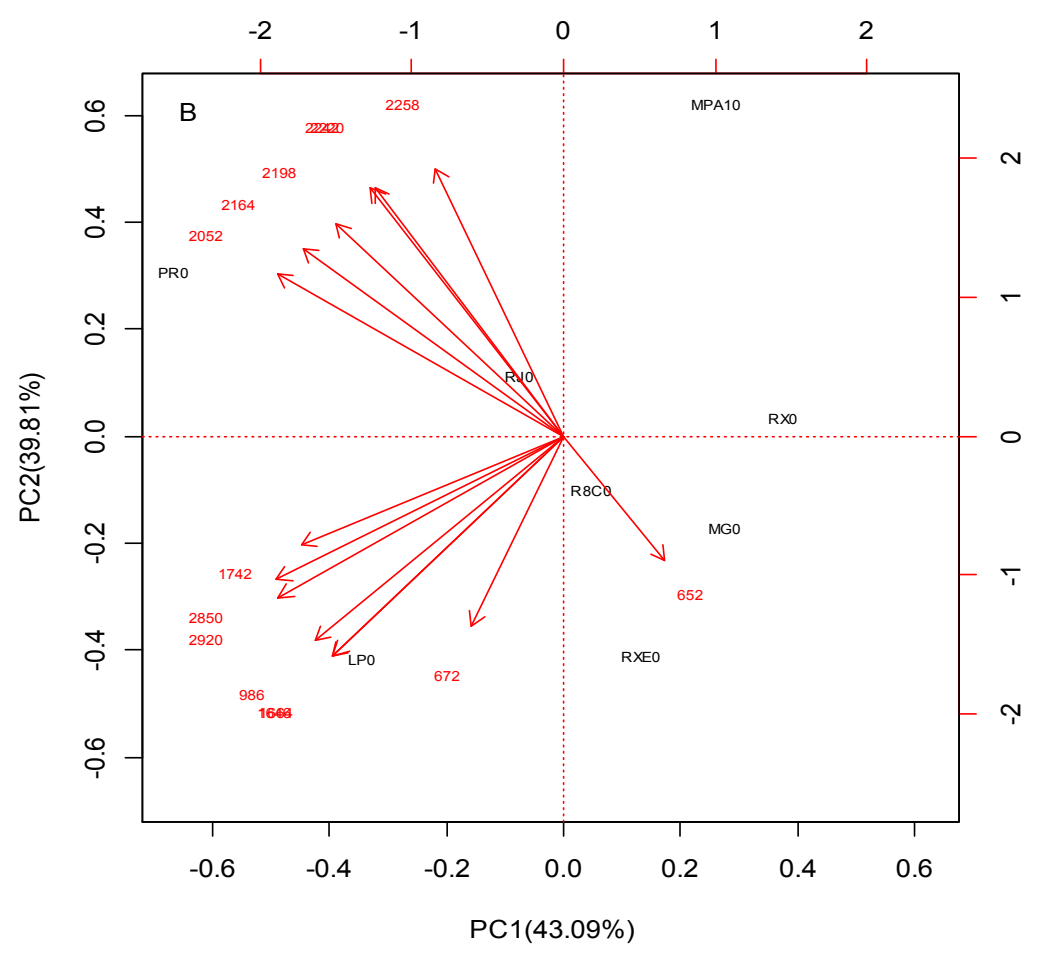




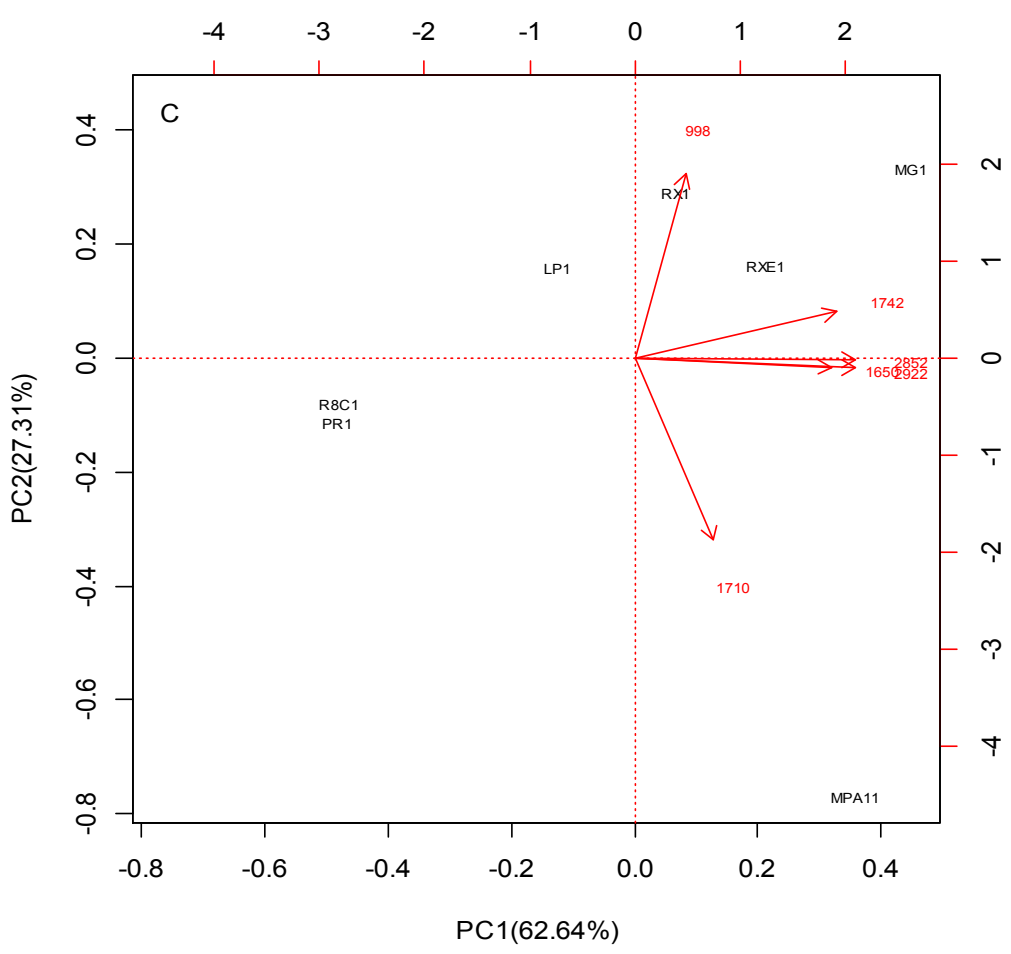

Fig. 2. Score and loading plots of Principal component analysis (PCA) of the whole spectral range $\left(600-3000 \mathrm{~cm}^{-1}\right)$ showing the sample clustering according to their similarities. (B) Maze landraces produced during 2008 year, (C) 2009 cultivars

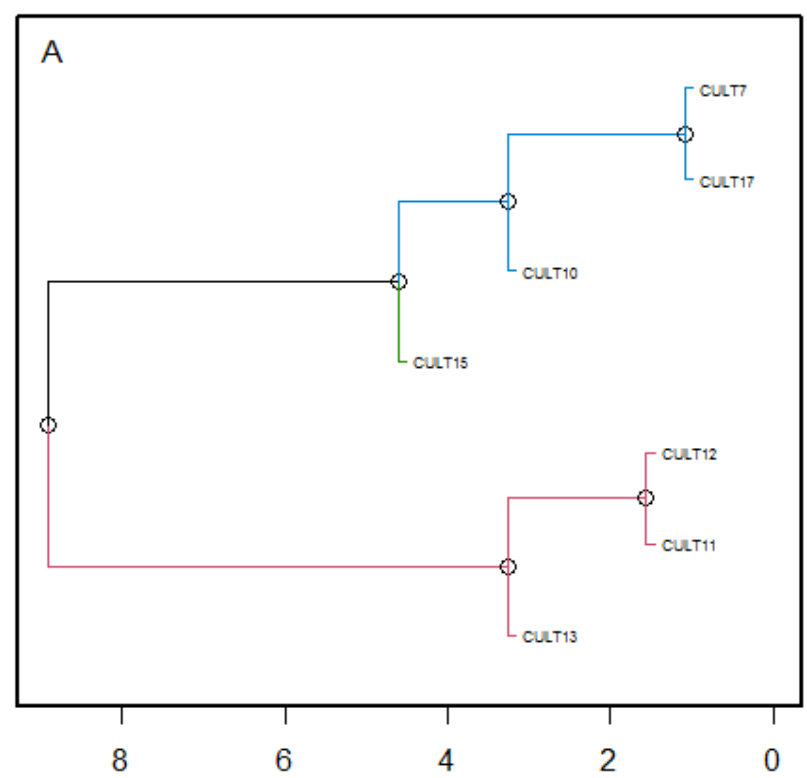

Fig. 3. Hierarchical cluster dendrogram (HCA) of the main peaks found in the spectra. (A) maize landraces produced during 2007 year 

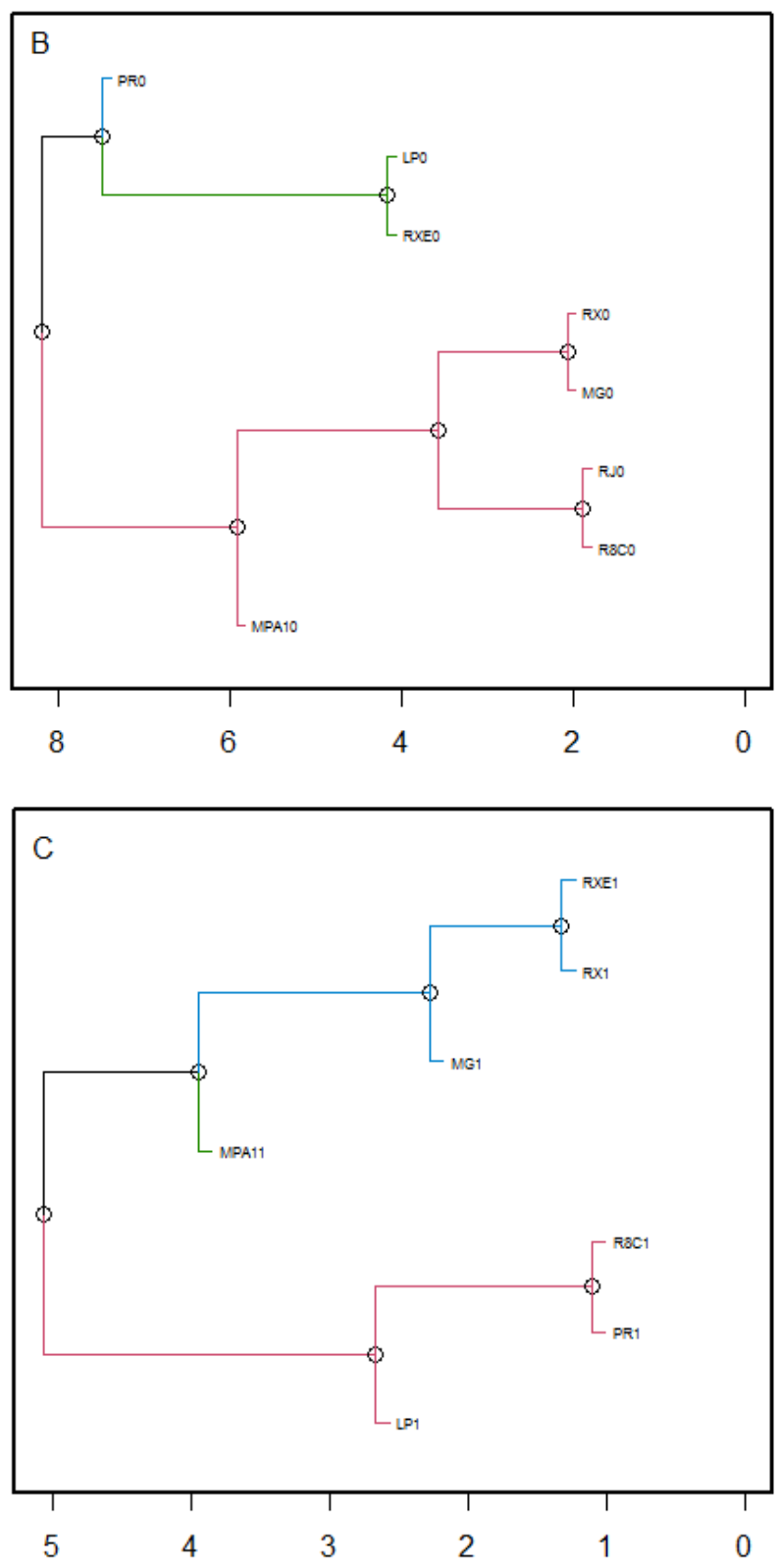

Fig. 3. Hierarchical cluster dendrogram (HCA) of the main peaks found in the spectra. (B) 2008, (C) maize landraces produced during 2009 year

Table 2. Assignment for the most characteristic ATR-FTIR bands found in maize landraces. Peaks and chemical group related is represented

\begin{tabular}{llll}
\hline Year of harvest & Chemical groups & Representative & ATR-IR wavenumber (1/cm) \\
\hline & & & 600 \\
& Monoterpnes & & 610 \\
& Sesquiterpenes & 624 \\
& Tetraterpenes & Lutein, beta-carotene & 640 \\
& Aminoacids & Methionine & 668 \\
& & 684 \\
& & 704 \\
\hline
\end{tabular}




\begin{tabular}{|c|c|c|c|}
\hline Year of harvest & Chemical groups & Representative & ATR-IR wavenumber $(1 / \mathrm{cm})$ \\
\hline \multirow[t]{13}{*}{2007} & & & 744 \\
\hline & & Lutein & 968 \\
\hline & Polysacharides & Amylose,amylopectin & 998 \\
\hline & & Amylose,amylopectin & 1012 \\
\hline & Lipids/fatty acids & & 2338 \\
\hline & & & 2360 \\
\hline & & & 3000 \\
\hline & Monoterpenes & & 652 \\
\hline & Tetraterpenes & & 672 \\
\hline & Polysacharides & Amylose,amylopectin & 986 \\
\hline & Proteins & & 1646 \\
\hline & & & 1664 \\
\hline & Lipids & & 1742 \\
\hline \multirow[t]{10}{*}{2008} & & & 2052 \\
\hline & & & 2164 \\
\hline & & & 2198 \\
\hline & & & 2220 \\
\hline & & & 2242 \\
\hline & & & 2258 \\
\hline & Lipids & & 2850 \\
\hline & & & 2920 \\
\hline & Polysacharides & Amylose,amylopectin & 998 \\
\hline & Proteins & & 1650 \\
\hline \multirow[t]{4}{*}{2009} & Lipids & & 1710 \\
\hline & & & 1742 \\
\hline & & & 2852 \\
\hline & & & 2922 \\
\hline
\end{tabular}

\section{CONCLUSIONS}

FT-IR technique coupled with chemometric tools (PCA, HCA) were capable in finding changes in chemical composition of maize landraces produced over different years. Similarities in maize samples were also found duo to carbohydrate composition. The major bands in FT-IR are related to carbohydrates, lipids and proteins. Trace signals of secondary metabolites were also found in cultivars according to year of harvest.

\section{ACKNOWLEDGEMENTS}

The authors acknowledge CNPq (National Counsel of Technological and Scientific Development) for financial support (Process $n$ 407323/2013-9). The project was also partially funded by the Project PropMine, funded by the agreement between Portuguese FCT and Brazilian CNPq.

\section{COMPETING INTERESTS}

Authors have declared that no competing interests exist.

\section{REFERENCES}

1. Dwivedi $S$, Ceccarelli $S$, Blair $M$, Upadhyaya H, Are A, Ortiz R. Landrace Germplasm for Improving Yield and Abiotic Stress Adaptation. Trends in Plant Science. 2016;21:31-42.

2. Strable J, Scanlon M. Maize (Zea mays): A Model organism for basic and applied research in plant biology. Cold Spring Harbor Protocols. 2009;132.

3. Vasconcelos A, Bonatti M, Schlindwein S, D'Agostini L, Homem L, Nelson R. Landraces as an adaptation strategy to climate change for smallholders in Santa Catarina, Southern Brazil. Land Use Policy. 2013;34:250-254.

4. Bellon M, Hellin J. Planting hybrids, keeping landraces: Agricultural modernization and tradition among smallscale maize farmers in chiapas, Mexico. World Development. 2011;39:1434-1443.

5. Mercer K, Martínez-Vásquez Á, Perales H. Asymmetrical local adaptation of maize landraces along an altitudinal gradient. Evolutionary Applications. 2008;1:489-500. 
6. Costa C, Maraschin M, Rocha M. An r package for the integrated analysis of metabolomics and spectral data. Computer Methods and Programs in Biomedicine. 2016;129:117-124.

7. Yi L, Dong N, Yun Y, Deng B, Ren D, Liu $\mathrm{S}$, Liang $\mathrm{Y}$. Chemometric methods in data processing of mass spectrometry-based metabolomics: A review. Analytica Chimica Acta. 2016;914:17-34.

8. Uarrota VG, Amante E, Demiate I, Vieira F, Delgadillo I, Maraschin M. Physicochemical, thermal, and pasting properties of flours and starches of eight Brazilian maize landraces (Zea mays L.). Food Hydrocolloids. 2013;30:614-624.

9. Kuhnen $S$, Ogliari J, Dias $P$, da Silva Santos M, Ferreira A, Bonham C, Wood K, Maraschin M. Metabolic Fingerprint of brazilian maize landraces silk (Stigma/Styles) using $\mathrm{nmr}$ spectroscopy and chemometric methods. J. Agric. Food Chem. 2010;58:2194-2200.

10. Schulz $H$, Baranska M. Identification and quantification of valuable plant substances by IR and Raman spectroscopy. Vibrational Spectroscopy. 2007;43:13-25.
11. Baranska M, Schulz H, Joubert E, Manley M. In Situ Flavonoid analysis by FT-Raman spectroscopy: Identification, distribution, and quantification of aspalathin in green rooibos (Aspalathus linearis). Analytical Chemistry. 2006;78:7716-7721.

12. $\mathrm{R}$ Core Team. $\mathrm{R}$ : a language and environment for statistical computing. $R$ Foundation for Statistical Computing, Vienna, Austria; 2016.

Available:https://www.R-project.org/

13. Hanson BA. ChemoSpec: Exploratory chemometrics for spectroscopy. R package version 4.3.28; 2016. Available:github.com/bryanhanson/Chemo Spec

14. Beleites C, Sergo V. HyperSpec: A package to handle hyperspectral data sets in R', R package version 0.98-20150304; 2016.

Available:http://hyperspec.r-forge.rproject.org

15. McManus C. HyperChemoBridge: Bridge between hyperSpec \& ChemoSpec. R package version 1.1.3; 2014. Available:https://github.com/Chathurga/Hy perChemoBridge

(c) 2017 Uarrota et al.; This is an Open Access article distributed under the terms of the Creative Commons Attribution License (http://creativecommons.org/licenses/by/4.0), which permits unrestricted use, distribution, and reproduction in any medium, provided the original work is properly cited.

Peer-review history:

The peer review history for this paper can be accessed here: http://sciencedomain.org/review-history/21869 